Article

\title{
Investigating the Aging Effects of Biochar on Soil C and Si Dissolution and the Interactive Impact on Copper Immobilization
}

\author{
Shaojun Jiang ${ }^{1,2}$, Jiachen $\mathrm{Wu}^{1}$, Lianxin Duan ${ }^{1,2}$, Sheng Cheng ${ }^{1,2}$, Jian Huang ${ }^{1,2}$ and \\ Tao Chen 1,2,* \\ 1 School of the Environment, South China Normal University, Guangzhou 510006, China; \\ shaojunj93@163.com (S.J.); 15261826395@163.com (J.W.); duanlianxin1993@163.com (L.D.); \\ ShengC@m.scnu.edu.cn (S.C.); 18371807641@163.com (J.H.) \\ 2 Guangdong Provincial Key Laboratory of Chemical Pollution and Environmental Safety \& MOE Key \\ Laboratory of Theoretical Chemistry of Environment, South China Normal University, \\ Guangzhou 510006, China \\ * Correspondence: tao.chen@m.scnu.edu.cn; Tel./Fax: +86-20-39310187
}

Academic Editors: Farid Chemat, Hussein Znad, Chiara Bisio and Monica Pica Received: 1 June 2020; Accepted: 16 September 2020; Published: 21 September 2020

\begin{abstract}
Aging tests were used to investigate the long-term effects of BC on the immobilization of $\mathrm{Cu}$, and the soil silicon dissolution of three types soils (black soil, (BS), vegetable garden soil (VS) and red soil (RS)). Litchi branch biochars (BC) at 10\% (w/w) were incubated with three Cu (400 mg/kg) contaminated soils. The effect on soil properties of $\mathrm{pH}$, soil organic carbon (SOC), dissolved organic carbon (DOC) and available silicon content were investigated, along with the speciation distribution of $\mathrm{Cu}$. The results indicated that SOC, DOC, and available silicon content (except, BC300) increased with the application of BCs. On the other hand, the DTPA (diethylenetriaminepentaacetic acid) extractable $\mathrm{Cu}$ content in BS, VS and RS soils were reduced by $4-12 \%, 18-25 \%$, and $12-19 \%$, respectively. The Cu availability in all soils first increased, and then decreased during the aging process. The sum of the other four fractions, including the carbonate fraction and the inert component increased by $4-4.5 \%$ (BS), 1.4-2.1\% (VS), and 0.5-1\% (RS) respectively, over the long-term process. Moreover, during the whole aging process, the soil properties (such as $\mathrm{pH}, \mathrm{SOC}$, DOC and available silicon content) were almost stable. This study demonstrates that BCs, especially those produced at a higher temperature, are superior to those been produced at $300{ }^{\circ} \mathrm{C}$ in immobilizing $\mathrm{Cu}$ and releasing available silicon in soils. However, the remediation efficiencies were restricted by the soil type contamination status and remediation time.
\end{abstract}

Keywords: BC; sequential extraction; copper; soil remediation; carbon-silicon interaction

\section{Introduction}

Copper pollution in agricultural soils can occur from copper mining and directly or indirectly from anthropogenic sources [1]. This can cause crop yields to fall, as well as allow copper to enter the food chain. Although copper is an essential trace element for the human body, long-term excessive intake can cause copper to accumulate in the body and endanger health [1-4]. Due to its potential toxicity, persistence and irreversibility by the United States Environmental Protection Agency (USEPA) has listed $\mathrm{Cu}$ as priory control pollutant [5-7]. With increased public awareness of health and safety, soil contamination by $\mathrm{Cu}$ has gained attention, and requires proper remediation.

In-situ remediation of $\mathrm{Cu}$-contaminated soils is regarded as an effective, practicable, and environmentally friendly measure [8]. Biochar (BC) is the solid, carbon (C)-rich and silicon (Si)-rich product of heating biomass in a low oxygen environment (pyrolysis) [9-12]. Due to its highly 
porous micro-structure, active functional groups, high $\mathrm{pH}$; rich $\mathrm{Si}$ content; surface area; and cation exchange capacity (CEC), BC can effectively immobilize contaminants. It does this by adsorption, ion exchange, surface complexation and precipitation. A number of studies have highlighted that $\mathrm{BC}$ further reduces the risk of heavy metals contamination to humans and the surrounding ecosystem [13-18]. Recent studies have reported the successful applications of BC in soil remediation, in both the short and long-term. For instance, Rees et al. [19] observed a reduction in extractable cadmium (Cd), copper (Cu (II)), and other metals in soils after the addition of $80 \%$ coniferous and $20 \%$ hardwood BC after seven days. Uchimiya et al. [20] also found a reduction in $\mathrm{Cu}$ (II) and $\mathrm{Zn}$ (II), using toxicity characteristic leaching procedure (TCLP) extraction in a contaminated soil 7 day incubation experiment after addition of cottonseed hull BC. Likewise, Bian et al. [21] used wheat straw $\mathrm{BC}$ to treat agriculture land and consistently and significantly increased soil $\mathrm{pH}$, total organic carbon and observed reductions in $\mathrm{Cd}$ (II) and $\mathrm{Pb}$ (II) concentrations, following $\mathrm{CaCl}_{2}$ and DTPA extractions over a three year period. Li et al. [22] demonstrated the link between BC type and long-term (three years) immobilization of $\mathrm{Cd}$ and $\mathrm{Cu}$ in acidic paddy soils, and recommended that the readily oxidized $\mathrm{BC}$ be applied to the soil to reduce the risk of $\mathrm{Cd}$ and $\mathrm{Cu}$ exposure. These short-term and long-term studies demonstrate that the application of $\mathrm{BC}$ in soil remediation is feasible. However, the data on long-term effects of $\mathrm{BC}$ on the immobilization of heavy metals appear to be inconsistent. In lightly contaminated agriculture soil, Lucchini et al. [23] demonstrated that BC caused small changes in metal fractionation in soil, but no significant changes in total metal concentrations in soil or plants were observed after three years. Over three consecutive harvests, hardwood BC treatments increased the uptake of metals in ryegrass in the last two harvests compared to the first harvest [24]. These studies highlight that the effects of $B C$ on immobilizing heavy metals in soils need to be investigated in greater detail. Furthermore, the long-term immobilization of heavy metals in soils is affected by the aging process of BC $[22,25]$. BC undergoes a slowed growth rate with uncontrolled in-situ oxidation in soils, which leads to the formation of carboxylic, carbonylic, phenolic and other oxygen-containing functional groups on the surface of aged BC [22,25-29]. As, such, the aging process is not synchronized in soils of different types $[27,30,31]$.

Lots of studies have focused on the organic component of BCs after adding them to soil, because of their function in carbon sequestration and environmental remediation, such as the adsorption of contaminants by oxygen-containing functional groups [12,32,33]. However, the function and effects of $\mathrm{BC}$ on the inorganic components are unclear, especially for $\mathrm{BC}$ that have higher mineral content (silicon-containing component). On the one hand, BC acts as a potential bio-available Si source and, more importantly, along with $\mathrm{Si}$ and $\mathrm{Al}$ complexes from soil, results in an increase in Fe and soil organic matter [34]. For instance, the adsorption of silicic acid on $\mathrm{Al}$ or Fe oxides may promote a lower phosphate-fixation in acidic soils, thus improving the rate of available P. Silicic acid dissolved in the soil solution can be adsorbed into soil minerals, particularly Fe and Al oxides/hydroxides [35]. There is a general lack of knowledge about the effects of BC aging on silicon flow and pollutant control in soil systems. Silicon-rich biochar is considered a rich source of silicon materials [36]. Therefore, BC can be redefined as a silicon-improving material in soil. Liu et al. [37] reported that the effect of wheat straw BC on soil Si in different regions. Unfortunately, the interaction between soil-available Si content and carbon components with biochar during the aging process in soils was not fully understood. In addition, the stable organo-mineral ( $\mathrm{C}$ and $\mathrm{Si}$ ) fraction produced via the aging process between $\mathrm{BC}$ and minerals plays a vital role in the stabilization of heavy metals.

Based on the expounded data, we propose the hypothesis that the interaction between soil-available $\mathrm{Si}$ content and carbon components in biochar during the aging process assists $\mathrm{Cu}$ immobilization immediately following biochar amendment. To test this hypothesis, this study was set up to explore the relationship between $\mathrm{C}$ and $\mathrm{Si}$ in soil, as well as to determine the availability of $\mathrm{Cu}$ in three different soils, during the aging process. The oxidizability under accelerated aging of $\mathrm{BC}$ under wet-dry conditions was simulated in the laboratory to gain insights into the aging process of BC. Specifically, this study aims to: (1) compare the effect of $\mathrm{BC}$ under different aging processes on three soil properties, 
and the mobility $\mathrm{Cu}$ in soil over the course of a year, and (2) determine the relationship between $\mathrm{C}$ and $\mathrm{Si}$ in the soil, with added $\mathrm{BC}$, and as a result of stimulated aging.

\section{Materials and Methods}

\subsection{Soils and Biochar}

Three topsoil samples $(0-20 \mathrm{~cm})$ were collected from different site fields. one sample of black soil (BS) was collected from non-polluted agricultural fields near Harbin, China $\left(45^{\circ} 40^{\prime} \mathrm{N}\right.$ and $\left.126^{\circ} 35^{\prime} \mathrm{E}\right)$; Two samples of red soil (RS) and vegetable garden soil (VS) were collected from agricultural fields $\left(23^{\circ} 07^{\prime} \mathrm{N}\right.$ and $\left.113^{\circ} 43^{\prime} \mathrm{E}\right)$ and vegetable fields $\left(23^{\circ} 02^{\prime} \mathrm{N}\right.$ and $\left.113^{\circ} 43^{\prime} \mathrm{E}\right)$ in Guangzhou, China. The sample of RS and VS were classified as clay soil (Ultisols), BS was classified as sandy loam soil (Histosols). After collection, the samples were air-dried, and passed through $2 \mathrm{~mm}$ and $0.147 \mathrm{~mm}$ nylon sieves before using for further characterization analysis.

Litchi branches were collected from an orchard in ZengCheng District, Guangzhou City, Guangdong Province, south China $\left(23^{\circ} 41^{\prime} \mathrm{N}\right.$ and $\left.113^{\circ} 81^{\prime} \mathrm{E}\right)$. The BC preparation process followed the method outlined in a previous study [38]. The BCs obtained under oxygen-limited conditions of different temperatures were named $\mathrm{BC} 300$ and $\mathrm{BC} 600$, where the suffix number refers to the carbonization temperature. The properties of the soils and BC are listed in Tables S1 and S2.

\subsection{Experimental Design}

The evaluation of retention properties $\mathrm{Cu}^{2+}$ on $\mathrm{BC} 300$ and $\mathrm{BC} 600$, followed the method described by Lin et al. [39]. Briefly, an aliquot of $0.05 \mathrm{~g}$ BC sample was added to $50 \mathrm{~mL}$ centrifuges tubes (polypropylene) that contained $40 \mathrm{~mL}$ of $50 \mathrm{mg} / \mathrm{L} \mathrm{Cu}^{2+}$ solution and $0.01 \mathrm{M} \mathrm{NaOH}$ or $\mathrm{HCl}$ was used to adjust the solution $\mathrm{pH}$. Then, the tubes were shaken at $250 \mathrm{rpm}$ for $24 \mathrm{~h}$ at room temperature $\left(25^{\circ} \mathrm{C} \pm 2\right)$ using a horizontal shaker. The amount of metal adsorbed was also calculated following the method described by Lin et al. [39].

The soil was air-dried and sieved to remove impurities, such as stones and organic residues. The total $\mathrm{Cu}$ content was adjusted to $400 \mathrm{mg} / \mathrm{kg}$ by adding $\mathrm{Cu}\left(\mathrm{NO}_{3}\right)_{2}$ solutions, mixed thoroughly, and aged at room temperature for 1.5 months. This study included nine treatments: BS0, VS0 and RS0 (control, containing BS, VS and RS without BC amendment), BS1, VS1 and RS1 (containing, BS, VS and RS with $10 \%(w / w)$ BC300 amendment), BS2, VS2 and RS2 (containing, BS, VS and RS with $10 \%$ $(w / w)$ BC600 amendment). All treatments were performed in triplicate. The incubation experiment was conducted in a constant temperature room at $25^{\circ} \mathrm{C}$ with $65 \%$ relative humidity, under a wet and dry (wet-dry) cycle for one year. The samples were checked regularly, and water added to compensate for water loss every $10 \mathrm{~d}$ to maintain $80 \%$ water holding capacity (WHC), then air-dried in the nature environment. During the incubation, soil samples ( $\sim 50 \mathrm{~g})$ were collected on days $0,1,3,5,7,14,21$, $28,60,180$ and 365 from each pot after thoroughly mixing the soils. Soil samples were air-dried and sieved for further analysis.

\subsection{Chemical Analysis}

Soil properties, including $\mathrm{pH}$, organic matter, cation exchange capacity, available nitrogen and phosphorus contents and other physicochemical properties, were determined according to previously described methods [40]. Briefly, the $\mathrm{pH}$ (1:2.5 of soil:water), soil organic carbon (SOC) $\left(\mathrm{K}_{2} \mathrm{CrO}_{4}-\mathrm{H}_{2} \mathrm{SO}_{4}\right.$ oil-bath heating), cation exchange capacity (CEC) (1 M ammonium acetate leaching at $\mathrm{pH} 7.0)$, total $\mathrm{N}$ (TN) (N/C soil analyzer, Flash, EA, Milan, Italy), available P (AP) (Olsen method) and available K (AK) (1 M ammonium acetate extraction) were determined. The dissolved organic carbon (DOC) was determined extraction of the soil $(5 \mathrm{~g})$ with distilled water $(25 \mathrm{~mL})$ and shaking for $2 \mathrm{~h}$. The extract solution was filtered $(0.45 \mu \mathrm{m})$ prior to DOC determination using a TOC analyzer (TOC V-CPH, Jena, Germany). The available Si (acetate buffer method) from soil using the method adopted from $\mathrm{Yu}$ et al. [41]. The total $\mathrm{Cu}$, and plant-available $\mathrm{Cu}$ of soil were estimated according to the method 
by $\mathrm{Lu}$ [42]. Briefly, the total heavy metals in the soil were digested by $\mathrm{HNO}_{3}-\mathrm{HF}_{-} \mathrm{H}_{2} \mathrm{O}_{2}$ and the plant-available $\mathrm{Cu}$ of soils were extracted from the treated soil using diethylenetriaminepentaacetic acid (DTPA, pH 7.3). The different forms of $\mathrm{Cu}$ metal in soil were extracted following the method of Tessier [43], and the methods are summarized in Table S3. All samples were centrifuged at $3000 \mathrm{rpm}$ for $5 \mathrm{~min}$, then, the suspensions were filtered through a $0.45 \mu \mathrm{m}$ filter, acidified (with concentrated $\mathrm{HNO}_{3}$ ) and $\mathrm{Cu}$ concentrations were determined using an atomic absorption spectrophotometer (AAS, iCE 3500, Thermo Scientific, MA, USA).

\subsection{Data and Statistical Analysis}

In the study, the following parameters were evaluated:

(1) Effects of BC application on an increase or decrease in Si or DOC content in soil calculated by Equation (1):

$$
\mathrm{E}_{\mathrm{bc}}=\frac{[\text { Si content or DOC content in soil from objects with application of } \mathrm{BC}]}{[\text { Si content or DOC content in soil from objects without the application of } \mathrm{BC}]} \times 100 \%
$$

where, $\mathrm{E}_{\mathrm{bc}}$ - percent increase or decrease in Si content or DOC content in soil under amendment with BC.

(2) The immobilization effectiveness (IE) of $\mathrm{Cu}$ in soil was calculated by Equation (2):

$$
\operatorname{IE}(\mathrm{Cu})=\left(1-\frac{\mathrm{C}_{\mathrm{t}}}{\mathrm{C}_{\mathrm{o}}}\right) \times 100 \%
$$

where, $C_{t}$ and $C_{o}$ are the copper concentration in the leachate of the treated soil and control, respectively.

All the experiments were conducted in triplicate. Data are presented as means with standard deviations. Statistical analyses were performed using SPSS Statistics 19.0 software (IBM, Armonk, NY, USA). A one-way ANOVA with multiple comparisons by LSD test at $p<0.05$ significance level was used to determine differences. Graphs were prepared using Origin 9.0 (OriginLab Corp, Northampton, MA, USA).

\section{Results and Discussion}

\subsection{Soil Properties of Soil and BC}

The soil properties are summarized in Table S1. Analysis of the soil properties and the $\mathrm{pH}$ shows that there were differences among the collected soil samples. The $\mathrm{pH}$ values followed the order $\mathrm{BS}(\mathrm{pH}=6.15)>\mathrm{VS}(\mathrm{pH}=5.88)>\mathrm{RS}(\mathrm{pH}=4.86)$. Likewise, the highest and lowest SOC were observed in BS and RS, respectively, BS and RS were collected from north and south China, respectively, indicating the positive correlation between latitudes for different sites. Moreover, they had the highest extractable cation contents of available silicon and BS compared with the other soil samples. However, the lowest content of available silicon and low CEC values were observed in RS and VS. Prior to spiking with $\mathrm{Cu}$, these three soils were considered unpolluted, because the concentration of heavy metals, such as $\mathrm{Cu}, \mathrm{Pb}, \mathrm{Cd}$ and $\mathrm{Zn}$ concentration in soils all lower than the risk screening values for soil contamination of agricultural land (Table S1) [39]. In comparison, the DOC of BCs gradually decreased due increased degradation of carbon components at high temperatures. Noticeable, as shown in Table S2, the C content in BC gradually increases with the pyrolysis temperature increases, while the $\mathrm{H}, \mathrm{O}$, and $\mathrm{N}$ content continues to decrease, and the atomic ratios $\mathrm{H} / \mathrm{C}, \mathrm{O} / \mathrm{C}$, and $(\mathrm{O}+\mathrm{N}) / \mathrm{C}$ also decrease. These results indicate that biochar with a higher pyrolysis temperature has a higher degree of carbonization and a more complete $\pi$-conjugated aromatic structure [39]. Litchi BC morphology and the absorbent capacities have been discussed in the literature $[38,39,44]$ : the observed increase in the p-conjugated system, and metal-retention capability. Therefore, this was not considered in the current study. 


\subsection{Sorption Behavior of $C u$ by $B C s$}

The sorption capacities of $\mathrm{Cu}$, by different $\mathrm{BCs}$ are presented in Figure 1. The maximum adsorption capacities for $\mathrm{Cu}$ increased with the rising pyrolysis temperature from 24.33 (for BC300) to $67.23 \mathrm{mg} / \mathrm{g}$ (for BC600), respectively. Notably, the maximum adsorption capacity between BCs of different temperatures different higher than previous studies (Table S4). This can be attributed to the $\mathrm{pH}$, ash contents, functional groups and high CEC values of the BCs (Table S1). This result is consistent with other studies [45] and indicates the positive influence of BC inorganic compounds on metal immobilization in aqueous solutions. In addition, an amount of studies on the large surface area, pore structure and functional group of biochars indicated that metal immobilization was possible $[12,13,22]$. Interestingly, following BC treatment with sodium silicate, the Cu sorption capacities in BC300 + Si and BC600 + Si increased by $24 \%$ and 9\%, respectively, compared to BC 300 and BC600. Zhao et al. [46] from an adsorption study suggested that the addition of silicon not only enhanced the adsorption capacity of biochar, but also effectively resisted the decrease in the adsorption capacities on BCs after aging $\left(\mathrm{H}_{2} \mathrm{O}_{2}\right.$ and $\mathrm{H}_{2} \mathrm{SO}_{4}$ oxidation). Previous studies have also shown that silica particles might affect $C$ arrangement and structural composition by producing a Si-C coupling system in the biochar matrix [47]. As discussed above, BC modified with silicon shows potential for enhanced metal adsorption.

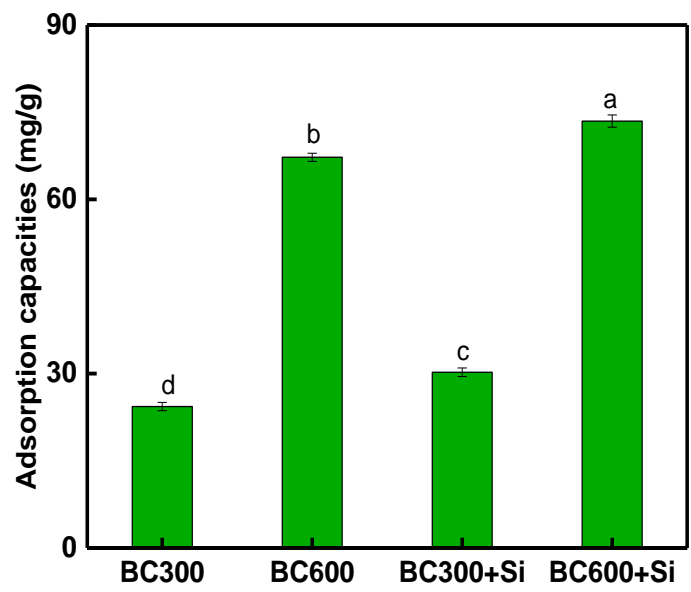

Figure 1. The adsorption capacities of $\mathrm{Cu}$ on different BC. BC300 + Si and BC600 + Si are BC modified with $5 \mathrm{M}$ sodium silicate. Values are the mean \pm standard deviations, different letters in the same column represent significant difference at $p<0.05$ ( $n=3$, LSD test).

\subsection{Effects of BC Amendment on Soil $p H, D O C$, and SOC}

The impact of BC on soil pH, DOC and SOC, over one year is shown in Figures 2 and 3, Table 1 and Table S5. Compared with the control, the application of $\mathrm{BC}$ slightly elevated soil $\mathrm{pH}$, and the influence was more obvious with the application of biochar that was higher in $\mathrm{pH}$ (Figure 2). The $\mathrm{pH}$ values of BS0, VSO and RS0 showed a slow, slightly increasing trend at certain time points, during the whole incubation process, which may be related to the neutrality of the deionized water used for wet-dry cycle (Figure 2). After BC treatment and aging, the pH of BS1 and BS2 on day 5 decreased to 6.39 and 6.60 compared with the $\mathrm{pH}$ on day 1 , and rapidly increase to 6.51 and 6.87, from day 3 to day 28 , followed by a slow decrease during the whole aging process (Figure 2a).

Table 1. Soil organic carbon (SOC), as affected by biochar (BC) application after one-year of aging. BS, black soil. VS, Vegetable garden soil. RS, red soil.

\begin{tabular}{cccccccccc}
\hline Treatment & BS0 & BS1 & BS2 & VS0 & VS1 & VS2 & RS0 & RS1 & RS2 \\
\hline SOC $(\%)$ & 3.32 & 5.07 & 4.38 & 1.53 & 3.27 & 2.37 & 0.90 & 2.41 & 1.85 \\
\hline
\end{tabular}



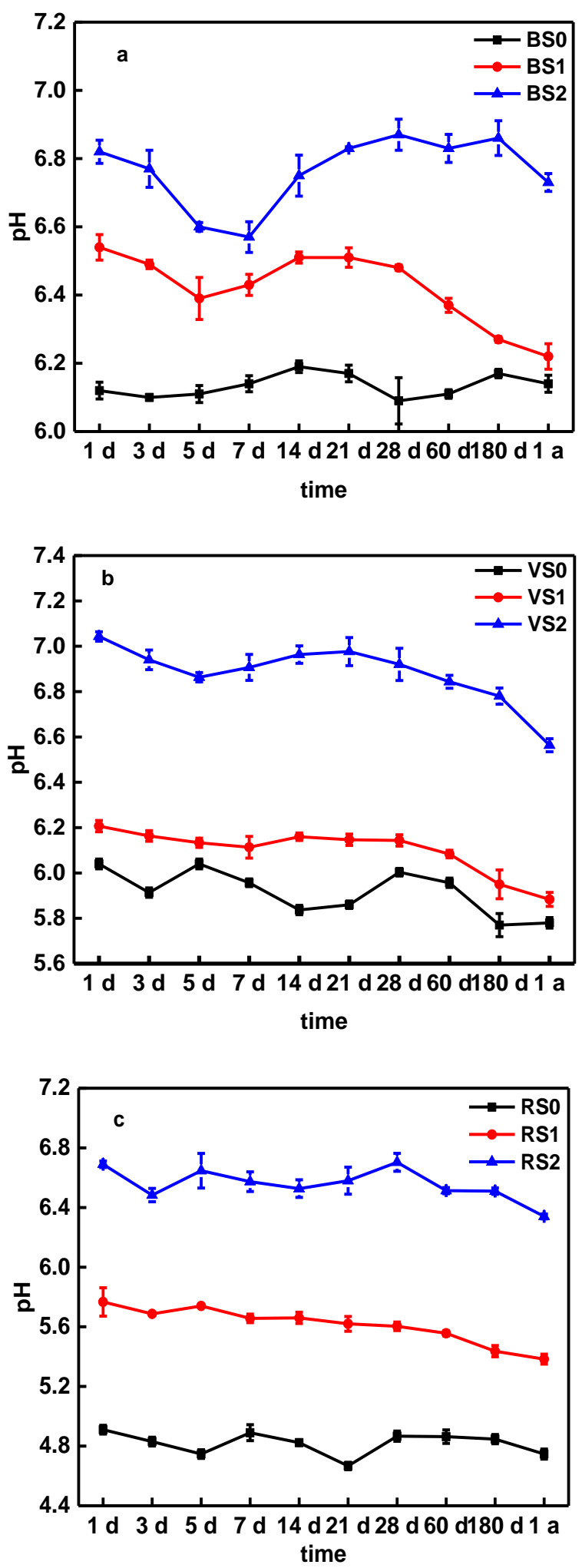

Figure 2. The change of $\mathrm{pH}$ in BS (a), VS (b) and RS (c) soils amended with biochars. Note: Error bars are standard deviations of the means $(n=3)$. (BS0: black soil, BS1: black soil + BC300, BS2: black soil + BC600, VS0: Vegetable garden soil, VS1: Vegetable garden soil + BC300, VS2: Vegetable garden soil + BC600, RS0, Red soil, RS1: Red soil + BC300, RS2: Red soil + BC600). 

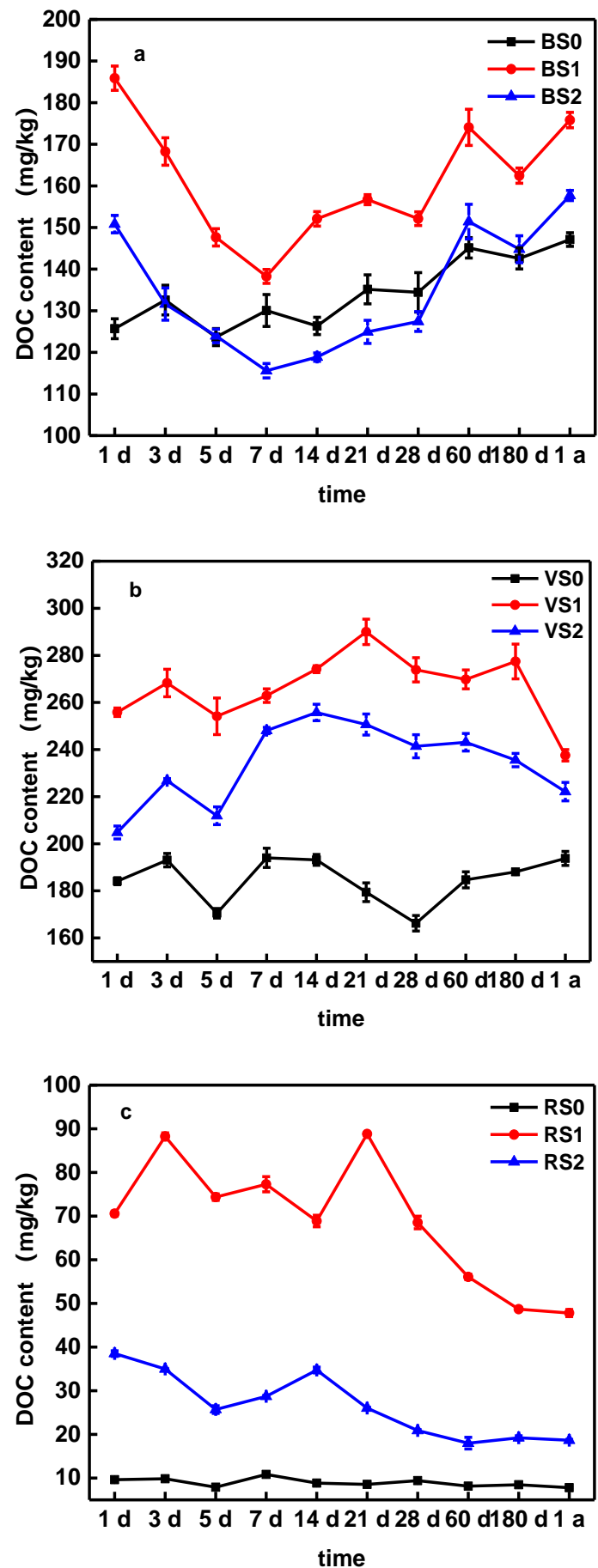

Figure 3. The change in DOC content in BS (a), VS (b) and RS (c) soils amended with biochars. Note: Error bars are standard deviations of the means $(n=3)$.

However, compared to BS the pH changes of VS and RS were different during aging process, mainly related to differences in soil types and properties. After biochar treatment and aging, the $\mathrm{pH}$ of VS1, VS2, RS1 and RS2 rapidly increased on day 1, then slowly decrease during the by one-year aging process (Figure $2 \mathrm{~b}, \mathrm{c}$ ). Previous studies have shown that BC during the 72-day aging process had the effect of improving the soil $\mathrm{pH}$, particularly in the early stage [48]. Wang et al. [33] showed that $\mathrm{pH}$ rapidly decreased from 0 to 30 days and slowly decreased from 31 to 95 days. $\mathrm{Xu}$ et al. [49] showed that $\mathrm{pH}(\mathrm{BC})$ value decreased from 8.20-10.7 to 7.5-9.7 after a 25-cycle aging test with BC, which can explain the soil slow decreased for $\mathrm{pH}$ during aging process (Figure 2).Furthermore, in a field experiment 
under a cucumber-sweet potato-rape rotation, Jiang et al. [44] showed that BC application can alter the soil acidity, while the natural aging of biochar in soil, cause the $\mathrm{pH}$ of soil to slowly decrease.

As SOC did not significantly change during the whole incubation process in any of the same treatments soil, we did not measure SOC at every time points, indicating that both types of biochar remained stable in the soil in the long term [22]. Changes in BC significantly increased the SOC content, compared with the control (Table 1). The increase in SOC was greater among VS and RS, compared to BS. Likewise, in soil treated with BC, DOC was significantly higher than in the untreated soil. The higher the pyrolysis temperature, the weaker the effect of improving soil DOC (Figure 3), which may due to the high DOC in BC300 (Table S1).

The DOC concentrations in the soil, in common with $\mathrm{pH}$, showed variation between collection periods. However, there was consistent decreasing trend in VS and RS in the latter part of the aging process, compared to the early soil (Figure 3b,c). With treatment by BS, however, the DOC content in BS1 and BS2 decreased from 1day to 7 days, and then increased from day 7 until the end of the process. This could be because BC improves the soil environment and enhances the adsorption of soil to organic components in the initial stage, but the labile organic compound in soil and biochar samples may be released during incubation after 7 days (Figure 3a). A number of studies have also reported that BC application could significantly increase DOC content in soils and decreased during long term aging process [24,50,51]. Li et al. [22] showed that the contents of soil organic matter (SOM) and DOC were significantly higher in the soil treated with biochar. There was a slow change in SOM during the 3-year period; DOC contents, on the other hand, changed over time, increasing steadily up to harvest one, and then decreasing over harvest 2 and 3. BC can modify soil DOC, in both quality and quantity by means of releasing DOC into the soil solution and/or stimulating the generation of more DOC from the soil organic carbon pool [51]. Moreover, Jiang et al. [44] reported that there was a downwards trend in DOC content after the aging process of crop cultivation. This may be attributed to the mineralization of $\mathrm{C}$ that occurs during the growing season, in the presence of $\mathrm{N}$ from inorganic fertilizer.

\subsection{Effect of Biochar on Soil Available Silicon}

Silicon, as a chemical modification in its soluble form, can effectively decrease heavy metal bioavailability [52]. The role of $\mathrm{Si}$ in $\mathrm{BC}$, on $\mathrm{Cu}$ mobility during the aging process of typical soils, such as BS, VS and RS, is not yet fully understood. The results of the concentrations of available $\mathrm{Si}$ in soil amended with BCs are shown in Figure 4. Figure 4 a show that BS1 decreased the available silicon by $11 \%$ and $12 \%$ compared with BS0 and BS2 in last stage, respectively. Due to the increase in available silicon content in the later stage of the aging process, BS2 is close to BS0 in the final stage. During the entire aging process, the available silicon content in BS1 was always lower than BS0.This is due to the BC300 having lower ash and $\mathrm{SiO}_{2}$ content (Table S1) and potentially an equilibrium has been reached between the Si adsorbed by soil and the Si dissolved from BC surface [32]. Compared with VS0 and RS0, the treatments VS1 and RS1 also show the same trend during o1 a aging process (Figure $4 b, c$ ).

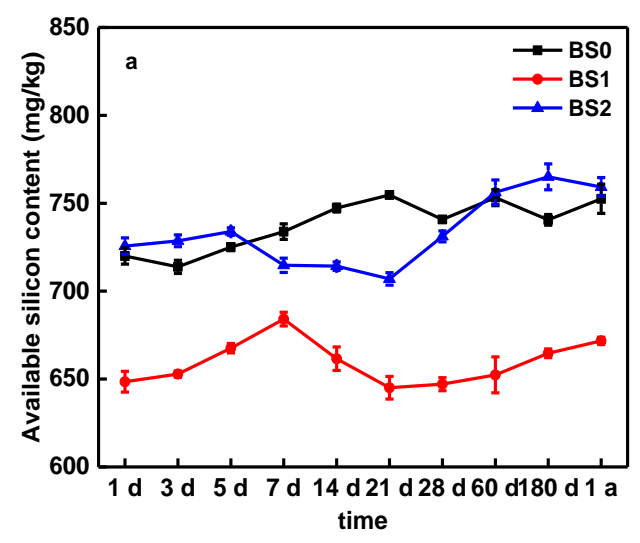

Figure 4. Cont. 

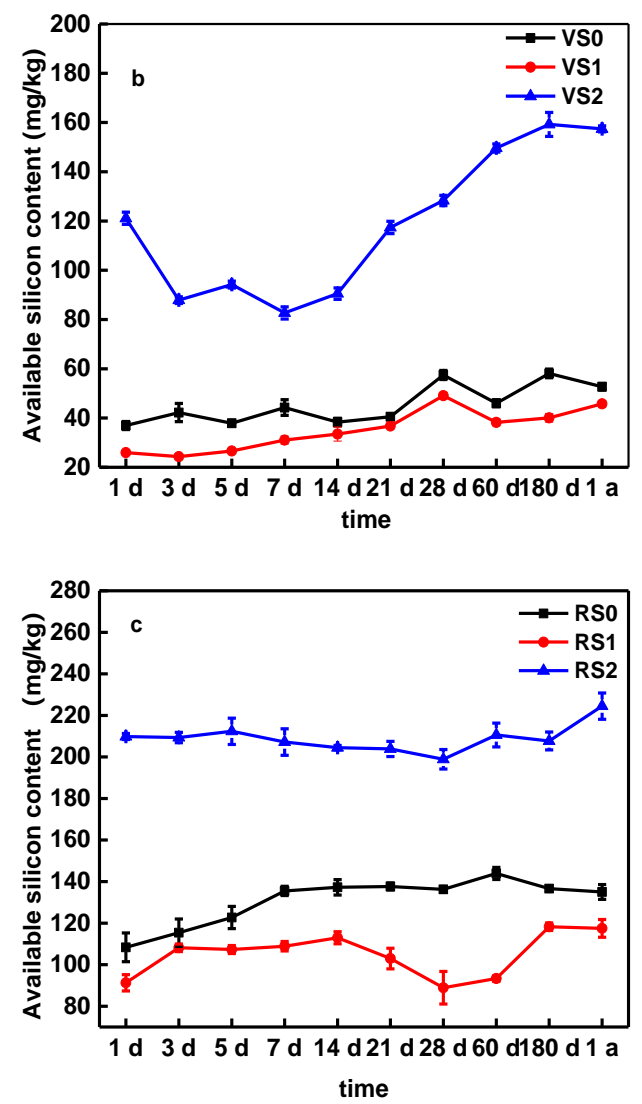

Figure 4. The change of available silicon content in BS (a), VS (b) and RS (c) soils amended with biochars. Note: Error bars are standard deviations of the means $(n=3)$.

Similarly, compared to VS0 and RS0, the available silicon of VS2 and RS2 significantly increased by $87-228 \%$ and $46-94 \%$, respectively, with the application of BC600 (Table S5). This result is due to the fact that $\mathrm{Si}$ the major component of the ash and BC derived from BC600 had a higher Si content, thus resulting in enhanced Si available for the lower Si soils, such as VS and RS. Previous studies have shown that BC can be used as a Si pool. It supports the dynamic process of Si release from BC modified soil [11,12,32,52].

Figure 4 also shows the silicon dissolution of the experimental values for different soil-BC mixtures. For BC600, the higher improvement in silicon dissolution in a low-silicon soil (RS) compared to that in a high-silicon soil (VS) treated with Si-rich BC (BC600) was observed. However, the opposite result was reported by Wang et al. [32]. For Si-rich BCs, the higher improvement in silicon dissolution in a high-silicon soil (HSS) compared to that in a low-silicon soil treated with Si-rich BCs was observed [32]. According this phenomenon, we suggest that the interaction between the soil and the BC may have caused the change, the $\mathrm{BC}$ and soil properties major the influence factor.

\subsection{DTPA-Extractable $\mathrm{Cu}$ in the Soil}

As shown in Figure 5, BC amendment reduced the mobility of $\mathrm{Cu}$ contents in soils, as seen by the reduction of DTPA-extractable metal content. By comparison, BC600 was more effective at metal immobilization than BC300, and achieved the highest reduction in the DTPA-extractable metal content in the three soils. This is because the adsorption capacities were higher than other BCs (Table 2). In addition, a clear difference was found between treatments with different soils. Xiao et al. [45] showed that BCs were more effective at reducing DTPA-extractable metal contents and metal immobilization than straw materials, this led them to believe that adsorption might not be the only mechanism governing metal immobilization in soils. Similarly, He et al. [53] demonstrated that the BC soil oxidation reaction would significantly affect the performance of $\mathrm{BC}$ on metal mobility and speciation 
in soils. Compared to BS, this result indicates that the BC (BC300 and BC600) significantly affects the immobilization of $\mathrm{Cu}$ in RS and VS. The $\mathrm{Cu}$ immobilization rates were higher in BS during the one-year aging process, which might be due to a lower concentration of available $\mathrm{Cu}$ in VS and RS, and because the bond between $\mathrm{Cu}$ and soil in BS was not as strong (Figure 5 and Table 2).
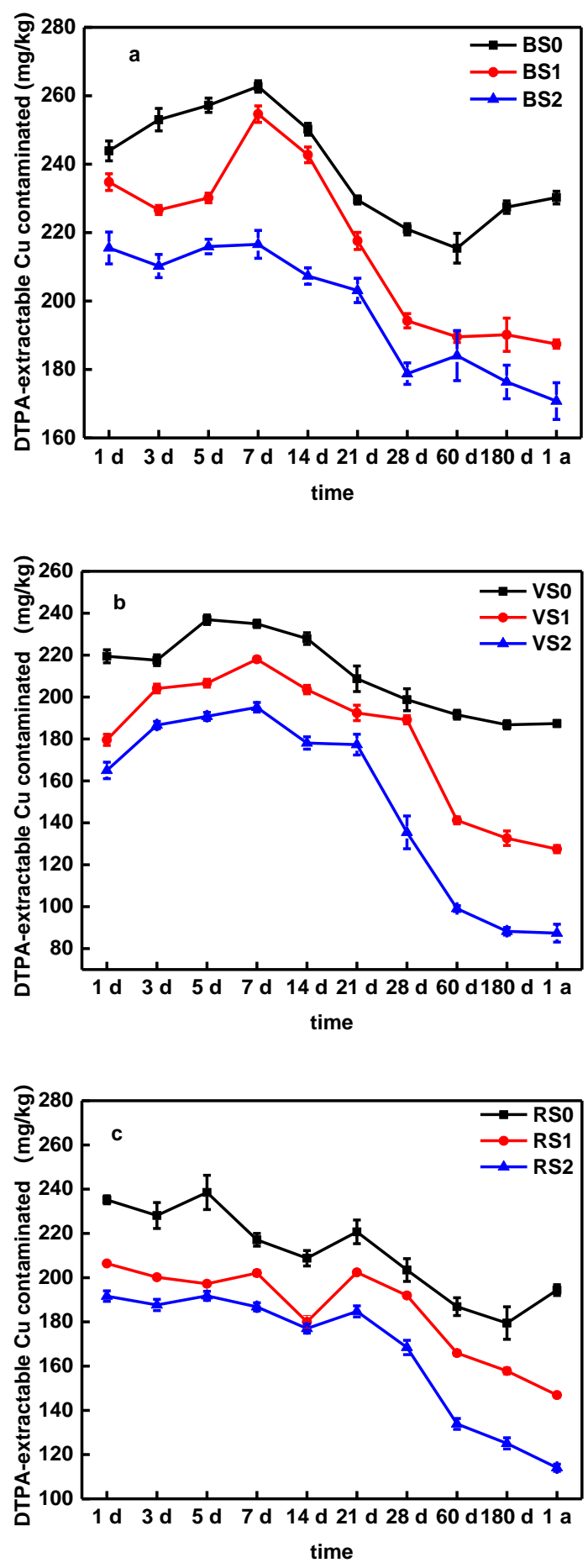

Figure 5. The change of DTPA-extractable Cu concentration in BS (a), VS (b) and RS (c) soils amended with biochars. Note: Error bars are standard deviations of the means $(n=3)$. 
Table 2. The immobilization effectiveness (IE) of $\mathrm{Cu}$ in three amended soils with biochars (BCs). Values are the mean \pm standard deviations, and the different letters in the same column represent that significant difference at $p<0.05(n=3$, LSD test).

\begin{tabular}{|c|c|c|c|c|c|c|c|}
\hline & \multirow{2}{*}{ Time } & \multicolumn{2}{|c|}{ BS } & \multicolumn{2}{|c|}{ VS } & \multicolumn{2}{|c|}{ RS } \\
\hline & & ВС 300 & BC600 & ВС 300 & BC600 & ВС300 & BC600 \\
\hline \multirow{10}{*}{$\mathrm{IE}(\mathrm{Cu}, \%)$} & $1 \mathrm{~d}$ & $4 \pm 0.25 \mathrm{f}$ & $12 \pm 0.85 \mathrm{~h}$ & $18 \pm 0.17 \mathrm{~d}$ & $25 \pm 0.53 \mathrm{~d}$ & $12 \pm 0.29 \mathrm{~d}$ & $19 \pm 0.24 \mathrm{e}$ \\
\hline & $3 \mathrm{~d}$ & $10 \pm 0.53 \mathrm{~d}$ & $17 \pm 0.66 \mathrm{f}, \mathrm{g}$ & $6 \pm 0.54 \mathrm{i}$ & $14 \pm 0.57 \mathrm{~g}$ & $12 \pm 0.37 \mathrm{~d}$ & $18 \pm 0.37 \mathrm{e}, \mathrm{f}$ \\
\hline & $5 \mathrm{~d}$ & $11 \pm 0.33 \mathrm{~d}$ & $16 \pm 0.33 \mathrm{f}, \mathrm{g}$ & $13 \pm 0.16 \mathrm{e}$ & $19 \pm 0.33 \mathrm{f}$ & $17 \pm 0.41 \mathrm{~b}$ & $20 \pm 0.76 \mathrm{~d}$ \\
\hline & $7 \mathrm{~d}$ & $3 \pm 0.21 \mathrm{~g}$ & $18 \pm 0.57 \mathrm{~d}, \mathrm{e}$ & $7 \pm 0.21 \mathrm{~h}$ & $17 \pm 0.16 \mathrm{~g}$ & $7 \pm 0.34 \mathrm{e}$ & $14 \pm 0.54 \mathrm{i}$ \\
\hline & $14 \mathrm{~d}$ & $3 \pm 0.08 \mathrm{~g}$ & $17 \pm 0.49 \mathrm{e}, \mathrm{f}$ & $11 \pm 0.22 \mathrm{f}$ & $22 \pm 0.24 \mathrm{e}$ & $14 \pm 0.49 c$ & $15 \pm 0.37 \mathrm{~h}, \mathrm{i}$ \\
\hline & $21 \mathrm{~d}$ & $5 \pm 0.29 \mathrm{e}$ & $12 \pm 0.24 \mathrm{~h}$ & $8 \pm 0.47 \mathrm{~g}$ & $15 \pm 0.49 \mathrm{i}$ & $8 \pm 0.29 \mathrm{e}$ & $16 \pm 0.24 \mathrm{~g}, \mathrm{~h}$ \\
\hline & $28 \mathrm{~d}$ & $12 \pm 0.22 c$ & $19 \pm 0.57 \mathrm{c}, \mathrm{d}$ & $5 \pm 0.21 \mathrm{j}$ & $32 \pm 0.21 \mathrm{c}$ & $6 \pm 0.17 f$ & $17 \pm 0.24 \mathrm{f}, \mathrm{g}$ \\
\hline & $60 \mathrm{~d}$ & $12 \pm 0.25 c$ & $15 \pm 0.93 \mathrm{~g}$ & $26 \pm 0.53 c$ & $48 \pm 0.33 b$ & $11 \pm 0.29 \mathrm{~d}$ & $28 \pm 0.33 c$ \\
\hline & $180 \mathrm{~d}$ & $16 \pm 0.22 b$ & $22 \pm 0.24 \mathrm{~b}$ & $29 \pm 0.45 b$ & $53 \pm 0.08 a$ & $12 \pm 0.17 \mathrm{~d}$ & $30 \pm 0.54 b$ \\
\hline & $1 \mathrm{a}$ & $19 \pm 0.12 \mathrm{a}$ & $26 \pm 0.41 \mathrm{a}$ & $32 \pm 0.39 \mathrm{a}$ & $53 \pm 0.49 a$ & $24 \pm 0.37 \mathrm{a}$ & $41 \pm 0.76 \mathrm{a}$ \\
\hline
\end{tabular}

Beesley and Dickinson [54] showed that the application of hardwood-derived BC increased the concentrations of DOC, which has an adverse effect on the immobilization of $\mathrm{Cu}$. Therefore, the DTPA-extractable $\mathrm{Cu}$ contents higher than other soils during one-year aging process is probably due to the increase in DOC (Figure 3) and SOC (Table S1) in the BS treatments (BS0, BS1 and BS2). In terms of the change trends, the $\mathrm{Cu}$ availability in nine treatments fluctuated sight, but generally showed an increase-decrease trend. For BS, the DTPA-extractable $\mathrm{Cu}$ concentration decreased from $215 \mathrm{mg} / \mathrm{kg}$ on day 1 to $170 \mathrm{mg} / \mathrm{kg}$ on one year with BC600 application (Figure 5a). The DTPA-extractable $\mathrm{Cu}$ concentration in BS1 fluctuated between 187 and $234 \mathrm{mg} / \mathrm{kg}$, accounting for $47-58 \%$ of the BS total $\mathrm{Cu}$ on the incubation (Figure 5a). Compared to BS, the DTPA-extractable $\mathrm{Cu}$ concentration in VS and RS also have be similar on trend during one-year aging process (Figure 5). The changes in $\mathrm{Cu}$ availability in soils reflected that the transport and transformation processes between soil and $\mathrm{BC}$ were dynamic during the aging process.

Taking into consideration the $\mathrm{pH}$ value (Figure 2), DOC (Figure 3) and available silicon content (Figure 4), we suggest that the interaction between these factors and the soil DTPA-extractable $\mathrm{Cu}$ may have caused the change in $\mathrm{Cu}$ availability. Previous works [22,24,45,52] have also shown that an increase in soil $\mathrm{pH}, \mathrm{DOC}$ and $\mathrm{Si}$ content after BC application could reduce the mobility of metal and promote its transformation to a more stable state. The aging experiment reported by Shen et al. [17] showed that the $\mathrm{pH}$ of the biochar decreased after accelerated aging due to the loss of dissolved alkaline minerals, indicating the $\mathrm{pH}$ could be a mobilization mechanism of the $\mathrm{Cu}$ during accelerated aging. Li et al. [51] study showed that a BC induced DOC modification in soil alters the speciation of metal contaminants by changing soil conditions, which suggests that the biochar-DOM interaction is an important mechanism in determining the mobility of heavy metal contaminants in biochar amended soils. Moreover, silicon from BC, as a chemical amendment in its soluble form, can effectively decrease heavy metal bioavailability [52]. Therefore, the $\mathrm{pH}$ values of soil, DOC, available silicon content and DTPA-extractable $\mathrm{Cu}$ concentration are dynamic during the aging process with $\mathrm{BC}$ application, indicating there was a close relationship between them.

\subsection{Tessier Cu Fractions in the Soil}

The Tessier method was used to determine the five $\mathrm{Cu}$ fractions in the soil. The five $\mathrm{Cu}$ fractions in the soil were significantly affected in all nine-soil treatments during one-year aging process, compared with the early aging stage (i.e., on day 1). However, a slight change occurred at each time points: in general, F1 and the sum of F1 and F2 showed decreasing trends. Hence in this study, we only evaluated and compared the five $\mathrm{Cu}$ fractions at the last stage (i.e., at one year). Figure 6 shows the fractionation of $\mathrm{Cu}$ in different treatments. We can see that the $\mathrm{Cu}$ bound to Fe and $\mathrm{Mn}$ oxide (F3), 
organic matter (F4) and the residual fraction (F5) covers over $68-89 \%$ of its total content in almost all the treatments.

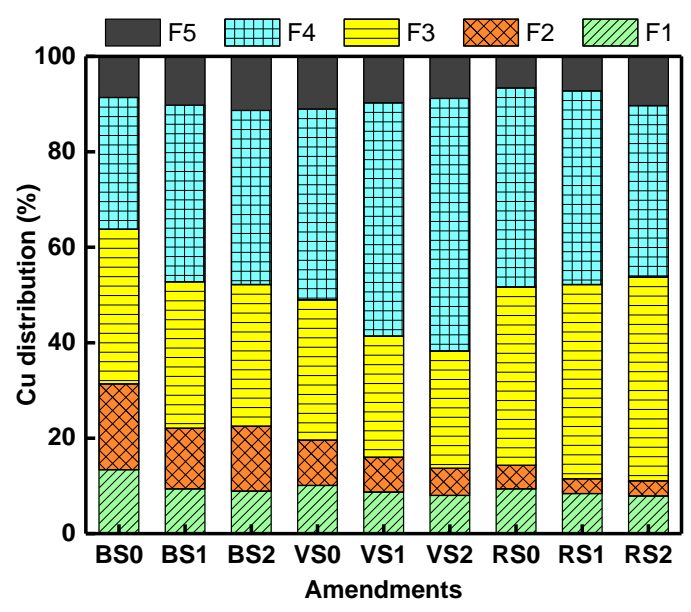

Figure 6. $\mathrm{Cu}$ fractionations of soils after 1a incubation with different $\mathrm{BC}$ amendments. F1, exchangeable; F2, carbonate bound; F3, Fe-Mn oxide bound; F4, organic matter bound; F5, residual fraction.

Comparing the three soils, F1 and the sum of F1 and F2 is higher in BS than in VS and RS. This also supports the high DTPA-extractable $\mathrm{Cu}$ concentration for BS (Figure 6). The sum of F1 and F2 of BS0, BS1 and BS2 were 31\%, 22\% and 23\%, respectively, and higher than the VS and RS treatments; The phenomenon might occur because SOC (Table S1) and DOC (Figure 4) is high in the BS, both of which decreased the ability of $\mathrm{BC}$ to fixate $\mathrm{Cu}$ [54]. Although, Park et al. [10] reported that $\mathrm{Cu}$ is present as a more stable fraction complex in this soil, but we believe that $\mathrm{Cu}$ in artificially contaminated soil more easily complexes with DOC in the soil during the one-year aging, enabling high SOC and DOC content. It is well known that $\mathrm{Pb}$ in F3, F4, and F5 is an inert component. While, easily exchangeable $\mathrm{Cu}(\mathrm{F} 1)$ is directly related to its bioavailability, and $\mathrm{Cu}$ bound to carbonates (F2) can be converted to bioavailable component as soil $\mathrm{pH}$ decreases. Meng et al. [48] indicated that $\mathrm{BC}$ continuously immobilized the bioavailable metal fraction in the soil during simulation of the actual aging process over 8 years. Therefore, the sum of the other four fractions including the carbonate fraction, F3, F4 and F5 all significantly increased in the long-term process.

\subsection{Limitation and Environmental Implication}

As demonstrated above, biochar is capable of immobilizing $\mathrm{Cu}$ in soils. However, soil properties, such as $\mathrm{pH}, \mathrm{SOC}$ and $\mathrm{DOC}$, and the properties of $\mathrm{BC}$ and the aging time, all affect the of efficiency of metal immobilization. As shown in Figure 2, the application of $\mathrm{BC}$ facilitated the stabilization of $\mathrm{pH}$ in the soil, but in the long-term aging process, the soil $\mathrm{pH}$ decreased. Therefore, in order to maintain the long-term immobilization of $\mathrm{Cu}$ in soils by $\mathrm{BC}$, it is appropriate to add new $\mathrm{BC}$ in the long-term amended stages of soil. $\mathrm{BC}$ also plays a significant role in various terrestrial biogeochemical processes of Si and C (Figures 3 and 4): however, the Si content in BC for amended pollution has not caused issues. In this study, we first considered the available silicon content, in relation to $\mathrm{Cu}$ immobilization during aging process. The results show that the release of available Si is important to the fixation of $\mathrm{Cu}$, which is consistent with the experimental results (Figure 1).

Moreover, the effect of $\mathrm{BC}$ on soil Si in different soils was investigated, our results were contradictory to other studies, e.g., Wang et al. [32] with regards to whether the available Si content of soil increased or decreased after BC amendment. This may be due to feedstocks of BC and soil properties. More studies are needed to focus on the carbon-silicon biogeochemical cycles and the heavy metal transport distribution between soil and water ecosystems. On the other hand, our result indicate that BC continuously immobilized the bioavailable $\mathrm{Cu}$ fraction in the soil (Figures 5 and 6), and $\mathrm{BC}$ has been applied to heavy metal contaminated soils as a metal stabilizing method, but it is unclear when and in 
what form the fixed heavy metals are released again. Further studies should focus on combining the $\mathrm{Si}$ source with the heavy metal (BC or soil) in contaminated soil during the aging process.

\section{Conclusions}

In this study, the addition of $\mathrm{BC}$ facilitated the immobilization of $\mathrm{Cu}$ in three soils types. However, the efficiency was affected by both the properties of the $\mathrm{BC}$ and the incubation time, as well as soil type. BC may not perform well in $\mathrm{Cu}$ contaminated soils with high SOC and DOC content. In comparison, the addition of BC enhanced soil DOC and $\mathrm{pH}$ value in VS and RS and significantly decreased the available Si content in both BS1 and BS2 during the aging process. Moreover, all the treatments significantly increased the SOC content. Generally, BCs, especially those high in $\mathrm{pH}$ and high ash content, had a better performance on soil $\mathrm{Cu}$ immobilization, and $\mathrm{BC}$ application facilitated the transformation of $\mathrm{Cu}$ speciation from F1 or F2 into a stable fraction. Although BC application reduced the extractable $\mathrm{Cu}$ contents in DTPA-extracts, the remediation performance was not satisfactory, especially for BS soil treatment due to the high DTPA-extractable $\mathrm{Cu}$ concentration during the whole aging process. This study showed that field applications of BC in heavy-metal associated soil remediation must consider the soil type and region attributes into account, and a study with respect to the soil type and the Si source (BC or soil) in contaminated soil during the aging process are important when $\mathrm{BC}$ applications are evaluated.

Supplementary Materials: The following are available online, Figure S1: The locations of the soil sampling sites, Table S1: The properties of the soil and BC, Table S2: Elemental compositions and atomic ratios of biochars, Table S3: Extractants used in sequential extraction of metal in soil, Table S4 Comparison of sorption capacity of $\mathrm{Cu}$ with biochars derived from different materials, Table S5: Effects of the application of BC on an increase/decrease in silicon content/DOC content in soil.

Author Contributions: Data curation, S.J., J.W. and S.C.; Funding acquisition, T.C.; Investigation, S.J., J.W. and J.H.; Methodology, L.D.; Software, S.C.; Writing—original draft, S.J.; Writing—review \& editing, L.D. and T.C. All authors have read and agreed to the published version of the manuscript.

Funding: This work was supported by grants from the Guangdong Provincial Science and Technology Program (2015B020237003) and Provincial Science and Technology Plan Project of Guangdong Province (2018SG00118).

Conflicts of Interest: The authors declare no conflict of interest.

\section{References}

1. Xu, X.; Huang, R.; Liu, J.; Shu, Y. Fractionation and release of $\mathrm{Cd}, \mathrm{Cu}, \mathrm{Pb}, \mathrm{Mn}$, and $\mathrm{Zn}$ from historically contaminated river sediment in Southern China: Effect of time and Ph. Environ. Toxicol. Chem. 2019, 38, 464-473. [CrossRef] [PubMed]

2. Qu, C.; Shi, W.; Guo, J.; Fang, B.; Wang, S.; Giesy, J.P.; Holm, P.E. China's soil pollution control: Choices and challenges. Environ. Sci. Technol. 2016, 50, 13181-13183. [CrossRef]

3. Niu, L.; Yang, F.; Xu, C.; Yang, H.; Liu, W. Status of metal accumulation in farmland soils across China: From distribution to risk assessment. Environ. Pollut. 2013, 176, 55-62. [CrossRef]

4. Lu, A.; Wang, J.; Qin, X.; Wang, K.; Han, P.; Zhang, S. Multivariate and geostatistical analyses of the spatial distribution and origin of heavy metals in the agricultural soils in Shunyi, Beijing, China. Sci. Total Environ. 2012, 425, 66-74. [CrossRef]

5. Chen, H.; Teng, Y.; Lu, S.; Wang, Y.; Wang, J. Contamination features and health risk of soil heavy metals in China. Sci. Total Environ. 2015, 512-513, 143-153. [CrossRef]

6. Chen, H.; Teng, Y.; Lu, S.; Wang, Y.; Wu, J.; Wang, J. Source apportionment and health risk assessment of trace metals in surface soils of Beijing metropolitan, China. Chemosphere 2016, 144, 1002-1011. [CrossRef]

7. Zhao, F.J.; Ma, Y.; Zhu, Y.G.; Tang, Z.; McGrath, S.P. Soil contamination in China: Current status and mitigation strategies. Environ. Sci. Technol. 2015, 49, 750-759. [CrossRef]

8. He, B.Y.; Yu, D.P.; Chen, Y.; Shi, J.L.; Xia, Y.; Li, Q.S.; Wang, L.L.; Ling, L.; Zeng, E.Y. Use of low-calcium cultivars to reduce cadmium uptake and accumulation in edible amaranth (Amaranthus mangostanus L.). Chemosphere 2017, 171, 588-594. [CrossRef] [PubMed] 
9. Cao, X.D.; Ma, L.N.; Gao, B.; Bandara, W.H. Dairy-manure derived biochar effectively sorbs lead and atrazine. Environ. Sci. Technol. 2009, 43, 3285-3291. [CrossRef]

10. Park, J.H.; Choppala, G.K.; Bolan, N.S.; Chung, J.W.; Chuasavathi, T. Biochar reduces the bioavailability and phytotoxicity of heavy metals. Plant Soil 2011, 348, 439-451. [CrossRef]

11. Xiao, X.; Chen, B.; Zhu, L. Transformation, morphology, and dissolution of silicon and carbon in rice straw-derived biochars under different pyrolytic temperatures. Environ. Sci. Technol. 2014, 48, 3411-3419. [CrossRef]

12. Wang, Y.; Xiao, X.; Xu, Y.; Chen, B. Environmental effects of silicon within biochar (Sichar) and carbon-silicon coupling mechanisms: A critical review. Environ. Sci. Technol. 2019, 53, 13570-13582. [CrossRef] [PubMed]

13. Shen, Z.; Jin, F.; Wang, F.; McMillan, O.; Al-Tabbaa, A. Sorption of lead by Salisbury biochar produced from British broadleaf hardwood. Bioresour. Technol. 2015, 193, 553-556. [CrossRef]

14. Shen, Z.; McMillan, O.; Jin, F.; Al-Tabbaa, A. Salisbury biochar did not affect the mobility or speciation of lead in kaolin in a short-term laboratory study. J. Hazard. Mater. 2016, 316, 214-220. [CrossRef]

15. Shen, Z.; Som, A.M.; Wang, F.; Jin, F.; McMillan, O.; Al-Tabbaa, A. Long-term impact of biochar on the immobilisation of nickel (II) and zinc (II) and the revegetation of a contaminated site. Sci. Total Environ. 2016, 542, 771-776. [CrossRef]

16. Shen, Z.; Zhang, Y.; McMillan, O.; Jin, F.; Al-Tabbaa, A. Characteristics and mechanisms of nickel adsorption on biochars produced from wheat straw pellets and rice husk. Environ. Sci. Pollut. Res. Int. 2017, 24, 12809-12819. [CrossRef]

17. Shen, Z.; Hou, D.; Zhao, B.; Xu, W.; Ok, Y.S.; Bolan, N.S.; Alessi, D.S. Stability of heavy metals in soil washing residue with and without biochar addition under accelerated ageing. Sci. Total Environ. 2018, 619-620, 185-193. [CrossRef]

18. Shen, Z.; Tian, D.; Zhang, X.; Tang, L.; Su, M.; Zhang, L.; Li, Z.; Hu, S.; Hou, D. Mechanisms of biochar assisted immobilization of $\mathrm{Pb}(2+)$ by bioapatite in aqueous solution. Chemosphere 2018, 190, 260-266. [CrossRef]

19. Rees, F.; Simonnot, M.O.; Morel, J.L. Short-term effects of biochar on soil heavy metal mobility are controlled by intra-particle diffusion and soil pH increase. Eur. J. Soil Sci. 2014, 65, 149-161. [CrossRef]

20. Uchimiya, M.; Bannon, D.I.; Wartelle, L.H. Retention of heavy metals by carboxyl functional groups of biochars in small arms range soil. J. Agric. Food Chem. 2012, 60, 1798-1809. [CrossRef]

21. Bian, R.; Joseph, S.; Cui, L.; Pan, G.; Li, L.; Liu, X.; Zhang, A.; Rutlidge, H.; Wong, S.; Chia, C.; et al. A three-year experiment confirms continuous immobilization of cadmium and lead in contaminated paddy field with biochar amendment. J. Hazard. Mater. 2014, 272, 121-128. [CrossRef] [PubMed]

22. Li, H.; Ye, X.; Geng, Z.; Zhou, H.; Guo, X.; Zhang, Y.; Zhao, H.; Wang, G. The influence of biochar type on long-term stabilization for $\mathrm{Cd}$ and $\mathrm{Cu}$ in contaminated paddy soils. J. Hazard. Mater. 2016, 304, 40-48. [CrossRef]

23. Lucchini, P.; Quilliam, R.S.; Deluca, T.H.; Vamerali, T.; Jones, D.L. Does biochar application alter heavy metal dynamics in agricultural soil? Agric. Ecosyst. Environ. 2014, 184, 149-157. [CrossRef]

24. Karami, N.; Clemente, R.; Moreno-Jimenez, E.; Lepp, N.W.; Beesley, L. Efficiency of green waste compost and biochar soil amendments for reducing lead and copper mobility and uptake to ryegrass. J. Hazard. Mater. 2011, 191, 41-48. [CrossRef]

25. Ren, X.; Wang, F.; Zhang, P.; Guo, J.; Sun, H. Aging effect of minerals on biochar properties and sorption capacities for atrazine and phenanthrene. Chemosphere 2018, 206, 51-58. [CrossRef]

26. Dong, X.; Li, G.; Lin, Q.; Zhao, X. Quantity and quality changes of biochar aged for 5 years in soil under field conditions. Catena 2017, 159, 136-143. [CrossRef]

27. Lawrinenko, M.; Laird, D.A.; Johnson, R.L.; Jing, D. Accelerated aging of biochars: Impact on anion exchange capacity. Carbon 2016, 103, 217-227. [CrossRef]

28. Sorrenti, G.; Masiello, C.A.; Dugan, B.; Toselli, M. Biochar physico-chemical properties as affected by environmental exposure. Sci. Total Environ. 2016, 563-564, 237-246. [CrossRef]

29. Hale, S.; Hanley, K.; Lehmann, J.; Zimmerman, A.; Cornelissen, G. Effects of chemical, biological, and physical aging as well as soil addition on the sorption of pyrene to activated carbon and biochar. Environ. Sci. Technol. 2011, 45, 10445-10453. [CrossRef]

30. Liu, G.; Chen, L.; Jiang, Z.; Zheng, H.; Dai, Y.; Luo, X.; Wang, Z. Aging impacts of low molecular weight organic acids, (LMWOAs) on furfural production residue-derived biochars: Porosity, functional properties, and inorganic minerals. Sci. Total Environ. 2017, 607-608, 1428-1436. [CrossRef] 
31. Zhang, X.; Sarmah, A.K.; Bolan, N.S.; He, L.; Lin, X.; Che, L.; Tang, C.; Wang, H. Effect of aging process on adsorption of diethyl phthalate in soils amended with bamboo biochar. Chemosphere 2016, 142, $28-34$. [CrossRef] [PubMed]

32. Wang, Y.; Xiao, X.; Chen, B. Biochar impacts on soil silicon dissolution kinetics and their interaction mechanisms. Sci. Rep. 2018, 8, 8040. [CrossRef] [PubMed]

33. Wang, Y.; Xiao, X.; Zhang, K.; Chen, B. Effects of biochar amendment on the soil silicon cycle in a soil-rice ecosystem. Environ. Pollut. 2019, 248, 823-833. [CrossRef] [PubMed]

34. Farmer, V.C.; Delbos, E.; Miller, J.D. The role of phytolith formation and dissolution in controlling concentrations of silica in soil solutions and streams. Geoderma 2005, 127, 71-79. [CrossRef]

35. Bruun Hansen, H.C.; Raben-Lange, B.; Raulund-Rasmussen, K.; Borggaard, O.K. Monosilicate adsorption by ferrihydrite and goethite at $\mathrm{pH}$ 3-6. Soil Sci. 1994, 158, 40-46. [CrossRef]

36. Ma, J.F.; Tamai, K.; Yamaji, N.; Mitani, N.; Konishi, S.; Katsuhara, M.; Ishiguro, M.; Murata, Y.; Yano, M. A silicon transporter in rice. Nature 2006, 440, 688-691. [CrossRef]

37. Liu, X.; Li, L.; Bian, R.; Chen, D.; Qu, J.; Wanjiru Kibue, G.; Pan, G.; Zhang, X.; Zheng, J.; Zheng, J. Effect of biochar amendment on soil-silicon availability and rice uptake. J. Plant Nutr. Soil Sci. 2014, 177, 91-96. [CrossRef]

38. Liu, J.; Jiang, S.; Chen, D.; Dai, G.; Wei, D.; Shu, Y. Activation of persulfate with biochar for degradation of bisphenol A in soil. Chem. Eng. J. 2020, 381, 122637. [CrossRef]

39. Lin, N.; Zhang, H.; Jia, Z.Z.; Huang, R.L.; Shu, Y.H. Adsorption of Pb(II) by biochars derived from three types of biomass. J. Agro-Environ. Sci. 2016, 35, 992-998.

40. Lu, R. Analytical Methods of Soil Agrochemistry; China Agricultural Science and Technology Publishing House: Beijing, China, 1999; pp. 18-99.

41. Yu, H.Y.; Ding, X.; Li, F.; Wang, X.; Zhang, S.; Yi, J.; Liu, C.; Xu, X.; Wang, Q. The availabilities of arsenic and cadmium in rice paddy fields from a mining area: The role of soil extractable and plant silicon. Environ. Pollut. 2016, 215, 258-265. [CrossRef]

42. Lu, K.; Yang, X.; Gielen, G.; Bolan, N.; Ok, Y.S.; Niazi, N.K.; Xu, S.; Yuan, G.; Chen, X.; Zhang, X.; et al. Effect of bamboo and rice straw biochars on the mobility and redistribution of heavy metals $(\mathrm{Cd}, \mathrm{Cu}, \mathrm{Pb}$ and Zn) in contaminated soil. J. Environ. Manag. 2017, 186, 285-292. [CrossRef]

43. Tessier, A.; Campbell, P.G.C.; Bisson, M. Sequential extraction procedure for the speciation of particular trace elements. Anal. Chem. 1979, 51, 844-851. [CrossRef]

44. Jiang, S.; Liu, J.; Wu, J.; Dai, G.; Wei, D.; Shu, Y. Assessing biochar application to immobilize Cd and Pb in a contaminated soil: A field experiment under a cucumber-sweet potato-rape rotation. Environ. Geochem. Health 2020, 1-12. [CrossRef]

45. Xiao, R.; Wang, P.; Mi, S.; Ali, A.; Liu, X.; Li, Y.; Guan, W.; Li, R.; Zhang, Z. Effects of crop straw and its derived biochar on the mobility and bioavailability in $\mathrm{Cd}$ and $\mathrm{Zn}$ in two smelter-contaminated alkaline soils. Ecotoxicol. Environ. Saf. 2019, 181, 155-163. [CrossRef]

46. Zhao, Z.; Nie, T.; Zhou, W. Enhanced biochar stabilities and adsorption properties for tetracycline by synthesizing silica-composited biochar. Environ. Pollut. 2019, 254, 113015. [CrossRef]

47. Ahmad, M.; Ahmad, M.; Usman, A.R.A.; Al-Faraj, A.S.; Abduljabbar, A.; Yong, S.O.; Al-Wabel, M.I. Date palm waste-derived biochar composites with silica and zeolite: Synthesis, characterization and implication for carbon stability and recalcitrant potential. Environ. Geochem. Health 2019, 41, 1687-1704. [CrossRef]

48. Zhuo, S.H.; Meng, W.; Xu, T.; Deng, Y.Y.; Lin, Z.B.; Wang, X.G. Transport and transformation of Cd between biochar and soil under combined dry-wet and freeze-thaw aging. Environ. Pollut. 2020, 263, 114449.

49. Xu, Z.; Xu, X.; Tsang, D.C.W.; Cao, X. Contrasting impacts of pre- and post-application aging of biochar on the immobilization of Cd in contaminated soils. Environ. Pollut. 2018, 242, 1362-1370. [CrossRef]

50. Wagner, A.; Kaupenjohann, M. Suitability of biochars (pyro- and hydrochars) for metal immobilization on former sewage-field soils. Eur. J. Soil Sci. 2014, 65, 139-148. [CrossRef]

51. Li, G.; Khan, S.; Ibrahim, M.; Sun, T.R.; Tang, J.F.; Cotner, J.B.; Xu, Y.Y. Biochars induced modification of dissolved organic matter (DOM) in soil and its impact on mobility and bioaccumulation of arsenic and cadmium. J. Hazard. Mater. 2018, 348, 100-108. [CrossRef]

52. Sui, F.; Wang, J.; Zuo, J.; Joseph, S.; Munroe, P.; Drosos, M.; Li, L.; Pan, G. Effect of amendment of biochar supplemented with Si on Cd mobility and rice uptake over three rice growing seasons in an acidic Cd-tainted paddy from central South China. Sci. Total Environ. 2019, 709, 136101. [CrossRef] 
53. He, E.; Yang, Y.; Xu, Z.; Qiu, H.; Yang, F.; Peijnenburg, W.; Zhang, W.; Qiu, R.; Wang, S.Z. Two years of aging influences the distribution and lability of metal(loid)s in a contaminated soil amended with different biochars. Sci. Total Environ. 2019, 673, 245-253. [CrossRef]

54. Beesley, L.; Dickinson, N. Carbon and trace element fluxes in the pore water of an urban soil following green waste compost, woody and biochar amendments, inoculated with the earthworm Lumbricus terrestris. Soil. Biol. Biochem. 2011, 43, 188-196. [CrossRef]

Sample Availability: Samples of the compounds, such as Sodium silicate, biochars and soils, are available from the authors.

(C) 2020 by the authors. Licensee MDPI, Basel, Switzerland. This article is an open access article distributed under the terms and conditions of the Creative Commons Attribution (CC BY) license (http://creativecommons.org/licenses/by/4.0/). 